\title{
ESTRUTURA E DINÂMICA DAS ORGANIZAÇÕES (ESCOLARES)
}

\author{
Rui de Lima e Silva \\ Mestrando em Ciências da Educação, Universidade Católica Portuguesa
}

\section{INTRODUÇÃO}

A análise do funcionamento das organizações, seja qual for a sua natureza, obriga a uma abordagem bastante complexa, onde é necessário ter em consideração inúmeros factores. Esses factores podem ser enquadrados nos mais diversos ramos, desde a sociologia ou psicossociologia das organizações às ciências do comportamento humano. A interpretação da escola como uma organização encontrou, durante o último século, diversas imagens que tendem a estar associadas às diferentes configurações definidas por teóricos das organizações. Mintzberg é um caso paradigmático no que concerne ao estudo das diferentes estruturas, dinâmicas e configurações organizacionais e tendo por base os seus trabalhos será possível compreender o funcionamento da escola ao mesmo tempo que se analisam os fluxos dentro dela existentes e de que forma tais aspectos poderão ajudar a compreender alguns problemas com os quais ela actualmente se vê confrontada. Mais do que dar resposta à necessidade de encontrar um modelo organizacional que melhore o funcionamento das organizações educativas, é importante reflectir sobre como estão a ser operadas as mudanças em todo o sistema educativo e de que forma os modelos organizacionais das escolas se estão a adaptar a essa nova realidade.

A escola tem-se enquadrado num modelo de Burocracia Profissional, característica de organizações que atribuem grande importância aos profissionais da produção, a quem é atribuído um elevado grau de autonomia, ideal para um sistema essencialmente normativo onde o principal objectivo é a produção com fins reprodutivos. Quando se abordam as questões da autonomia, administração e gestão escolar, democratização do ensino, participação activa da comunidade educativa, envolvimento de pais e encarregados de educação na vida da escola (Decreto-Lei 115/A-98, Lei n.․24/99) é necessário ponderar sobre como todas essas "novas" dinâmicas serão enquadradas nos modelos organizacionais que actualmente pontificam nas escolas portuguesas. Ao longo deste trabalho tentar-se-á dar a conhecer os princípios básicos da Teoria das Organizações de Henry Mintzberg e perceber de que forma esta nos poderá ajudar a compreender o funcionamento das escolas.

\section{ORGANIZAÇÃO}

O conceito de organização tem sido abordado pelos mais variados autores e neste contexto as suas definições tentam, de certa forma atribuir-lhe um carácter sistémico, onde as partes que a compõem são elemento chave no funcionamento das mesmas. Se por um lado, as organizações são tidas como agrupamentos de indivíduos construídos ou reconstruídos com objectivos específicos (Etzioni in Costa, 2003) em termos de dinâmica social, elas podem também constituir-se como um local onde cada indivíduo que a compõe actua para realizar os seus objectivos pessoais (Chanlat, 1993). 
Poder-se-ão ainda considerar, numa perspectiva mais ampla, as organizações como sistemas vivos, fortemente dependentes do meio que as rodeia e influencia directamente, e dos indivíduos que nela estão inseridos, também eles produtos desse ambiente exterior à organização. Assim sendo, a complexidade do estudo organizacional assume particular relevância, pois se existem diferentes tipos de organização, também há diferentes géneros de ambiente. (Morgan, 1996)

Interessa portanto, antes de analisar o funcionamento e as estruturas das organizações, atender a estas definições, por forma a considerá-las sempre sistemas complexos, dependentes de inúmeros factores e compostos por indivíduos e grupos de indivíduos com características próprias.

\section{O MODELO ORGANIZACIONAL}

Mintzberg, no seu livro "Estrutura e Dinâmica das Organizações", apresenta cinco estruturas existentes dentro das organizações: o vértice estratégico, a linha hierárquica, o centro operacional, a tecnoestrutura e o pessoal de apoio, cada um deles com funções específicas dentro do sistema, mas que podem interagir das mais variadas formas e mediante um variado leque de factores. Passemos então a enunciá-las, enquadrando-as sempre no contexto global do funcionamento das organizações.

\subsection{Vértice Estratégico}

É o topo da hierarquia, onde se processam a maior parte das decisões. É aqui que é delineada a estratégia e onde é feito o planeamento de como decorre todo o processo de produção. Esta estrutura tem a principal função de assegurar o cumprimento da missão de uma forma eficaz, mas é também responsável por todo o tipo de supervisão. Esta supervisão pode estar relacionada com a gestão de recursos e conflitos, com o controlo que passa pela revisão das actividades, ou pela comunicação directa ou indirecta com os elementos da organização. Acresce-lhe ainda o aspecto da responsabilidade para com toda a organização, e desta perante o ambiente que a rodeia. Como tal, além de comunicar com o interior do sistema, o vértice estratégico tem a responsabilidade de ser ele o elo de ligação com o ambiente envolvente, cabendo-Ihe desta forma a gestão das condições de fronteira organizacional. (Mintzberg, 1995)

Em termos das organizações escolares poderemos considerar o Conselho Executivo ou a Direcção como o vértice estratégico.

\subsection{Linha Hierárquica}

A linha hierárquica, ou utilizando o termo inglês, o Middle Management tem a principal função de estabelecer a ligação entre as diferentes partes da organização. Ele é composto por gestores intermédios que tentam dar resposta às diferentes necessidades existentes no sistema. Este é um centro nevrálgico de toda a estrutura, pois é por aqui que passa toda a informação e onde as estratégias são adaptadas, mediante a forma como está a funcionar o processo de produção. Cabe a esta parte, fazer ligação entre todos os elementos da estrutura, com particular destaque entre o Vértice Estratégico, que delineia as estratégias e faz o planeamento, e o Centro Operacional. Apesar de numa escola esta linha não ser evidente, poder-se-á considerar em algumas instituições particulares os coordenadores, como os indivíduos que estabelecem essa ponte entre a Direcção e os professores. 


\subsection{Centro Operacional}

Esta estrutura, também denominada "chão de fábrica", é onde se dá o processo de produção. O produto desta estrutura não é forçosamente um bem, como as organizações escolares ilustram facilmente. O produto das organizações pode ser um serviço, o que no caso atrás referido poder-se-á entender como as aprendizagens efectuadas pelas crianças. De qualquer forma, toda a organização vive em função do Centro Operacional, pois é para ele que ela existe. Como se entende facilmente, os professores são os operacionais e são eles que produzem, ou numa concepção de escola pós-moderna, promovem a "produção" das aprendizagens nos alunos.

\subsection{Tecnoestrutura}

Aqui, entende-se a tecnoestrutura como os analistas que não estando directamente envolvidos na produção, têm a capacidade de observar/avaliar todo o sistema e como este está a funcionar e que comunicando com os gestores da linha hierárquica, possibilitam uma constante adaptação do sistema às necessidades pontuais. Existe uma grande dificuldade em enquadrar esta estrutura num contexto organizacional de uma instituição escolar, uma vez que nos modelos de gestão escolar ela é inexistente ou são os próprios professores ou direcções que desempenham esse papel.

\subsection{Pessoal de Apoio}

Como o próprio nome indica, esta parte da organização, à semelhança da tecnoestrutura, não está envolvida directamente na produção, funcionando apenas como suporte de todo sistema. Os operacionais desta estrutura têm a função de sustentar e/ou promover todo o processo de produção, entendendo-se a promoção como a actividade desempenhada pelos departamentos de marketing que dão a conhecer ao meio exterior o produto da organização ou em alguns casos, ela própria. Uma vez que ao nível das escolas (em Portugal) essa promoção das instituições não está desenvolvida, o pessoal de apoio resume-se àqueles que sustentam todo o sistema e que são os auxiliares da acção educativa; os funcionários administrativos, pessoal de refeitório, bar, biblioteca, vigilantes e outros indivíduos que permitem o funcionamento de toda a organização.

\section{OS FLUXOS ORGANIZACIONAIS}

Percorridas que estão as diferentes partes da organização, interessa saber como elas se articulam entre si. Mintzberg (1995) afirma que estas são ligadas entre si por diferentes fluxos - de autoridade, de material de trabalho, de informação e de processos de decisão. 
Fig. 1

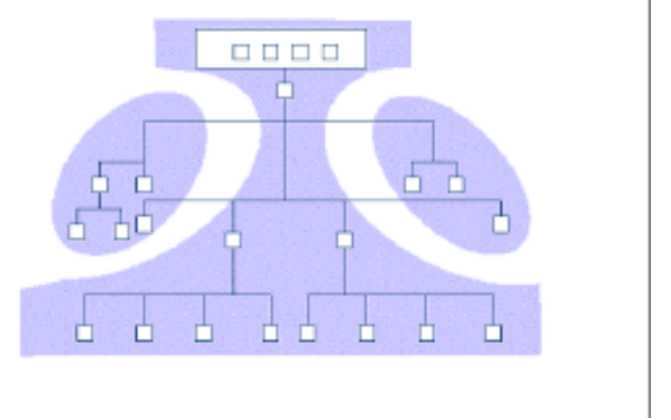

Os fluxos de autoridade formal foram muito apreciados pelos primeiros teóricos das organizações que através de um esquema, que se pode considerar uma espécie de mapa ou esqueleto da organização, deram origem ao denominado organizational chart, mas que nós, à semelhança dos francófonos, preferimos chamar organigrama e que de uma forma bastante sintética explica como os fluxos de autoridade percorrem a organização. Apesar de em alguns tipos de organizações este esquema não assumir grande relevância, até mesmo porque o funcionamento desta a isso não obriga, este fluxo deve ser sempre tido em consideração, uma vez que a autoridade é exercida maioritariamente segundo o organigrama definido (Fig.1).

Quanto aos fluxos de actividades, estas podem ser reguladas segundo o organigrama estabelecido pelo fluxo de autoridade formal, sendo que, neste caso todo o processo de produção e a própria informação inerente a este processo circulam, quer no sentido descendente ou no sentido ascendente segundo a hierarquia estabelecida (Fig.2). Desta forma o fluxo das actividades é sempre um processo muito lento, pois toda a comunicação existente na organização é obrigada a percorrer todos os elemento da estrutura hierárquica.

Fig. 2

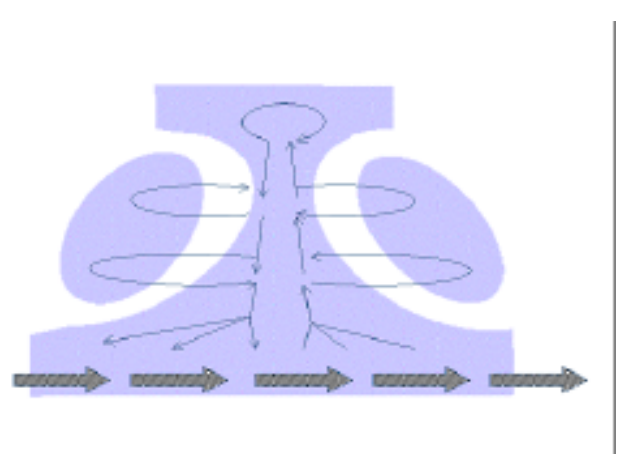

Fig. 3

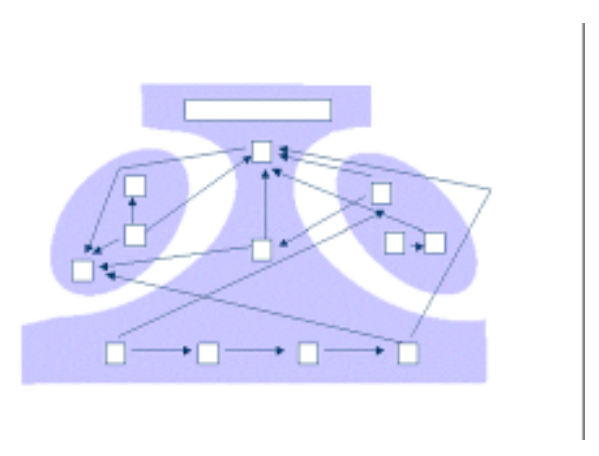

Se os fluxos de autoridade e das actividades reguladas obedecem a uma hierarquia definida por um organigrama, já os fluxos de comunicação podem ocorrer de uma forma completamente informal, em que uma informação pode partir de um elemento do centro operacional directamente para um gestor de topo, sendo isto o que Mintzberg (1995) descreve como uma quebra da ligação hierárquica (Fig.3). Este tipo de fluxos é o mais frequente na organizações pequenas ou recentes. Nas escolas este fluxo é o mais evidente, uma vez que a informação entre todos os elementos da organização escolar circula através da comunicação directa e informal. 
A comunicação informal dá origem ainda ao que Minzberg define como constelações de trabalho. Estes fluxos são explicados pela proximidade entre os diferentes elementos da organização, podendo esta proximidade dever-se ao facto dos indivíduos trabalharem numa mesma estrutura. Porém, estas constelações podem também ser compostas por indivíduos unidos pela necessidade que têm em comunicar dentro da organização, para a realização de determinadas tarefas ou funções que thes são incumbidas. Este fluxo pode ser bem ilustrado através do esquema em anexo (Fig.4), salientando-se a constelação formada por elementos da tecnoestrutura e da linha hierárquica, que pelas funções que detêm na organização são obrigados a estar em constante comunicação, o que de certa forma ajuda a compreender como se formam estas constelações que abrangem difere ntes partes da organização.

Fig. 4

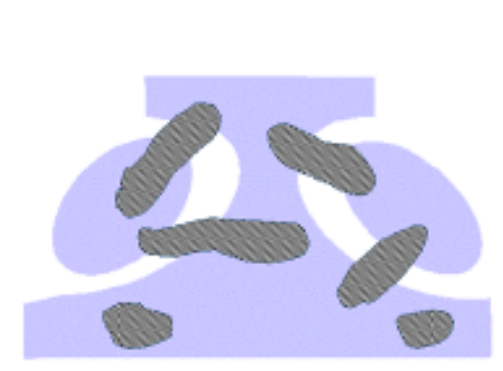

Fig. 5

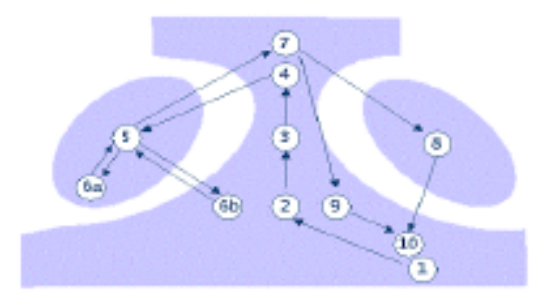

Por fim temos os fluxos como processos de decisão ad hoc, que atribuem elevada importância ao meio exterior, pois é para este que é desenvolvido o produto. A forma como este fluxo percorre o sistema organizacional contempla sempre a informação vinda do exterior, para uma constante inovação e adaptação às necessidade do meio envolvente, que como é óbvio, contempla os clientes. Sendo assim, a organização é tida como um sistema vivo que existe num ambiente mais amplo do qual depende em termos de satisfação das suas várias necessidades (Morgan, 1996) mas também para a qual desenvolve o seu produto.(Fig. 5)

No que respeita à realidade escolar, este é um fluxo que pode ser enquadrado num contexto cada vez mais actual, e onde a comunidade envolvente assume uma maior importância

na dinâmica educativa, enquadramento esse que será abordado na parte final deste trabalho.

Mintzberg define estes fluxos como estratos, que ao se sobreporem, explicam de uma forma bastante superficial o funcionamento das organizações. Sendo assim, ao observar-se o esquema com os diferentes fluxos representados, facilmente se percebe que as organizações são sistemas extremamente complexos e que contemplam uma grande variedade de factores. (Fig.6)

Fig. 6

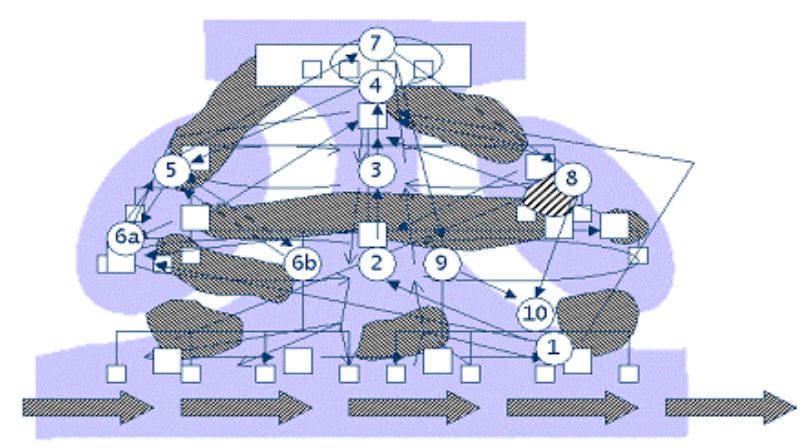




\section{AS CONFIGURAÇÕES ORGANIZACIONAIS}

Após a análise dos diferentes fluxos, interessa saber como estes influenciam o próprio funcionamento da organização e como as diferentes partes se articulam entre si mediante esses fluxos. Neste capítulo abordar-se-ão de uma forma bastante superficial as diferentes configurações apresentadas por Henry Mintzberg.

Fig. 6

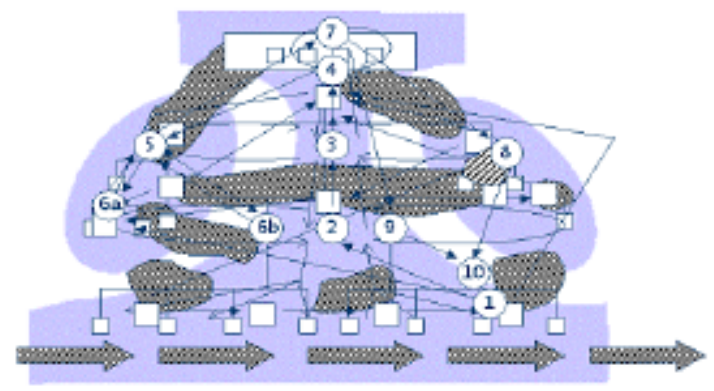

Fig. 7

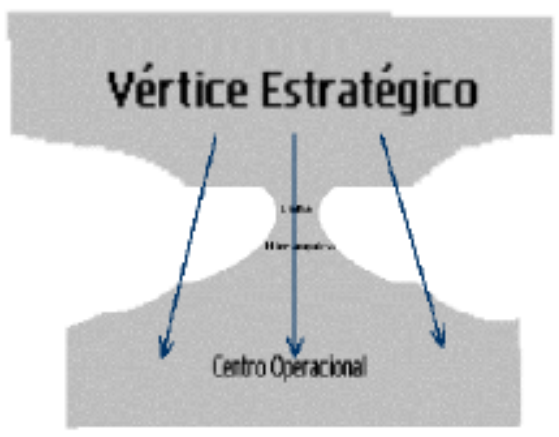

\subsection{Estrutura Simples}

Esta é uma configuração característica de pequenas organizações, que assentam numa liderança forte, habitualmente na figura de um indivíduo, que exerce a sua autoridade de uma maneira informal, através de uma supervisão directa. Nesta configuração, quer a linha hierárquica, quer a tecnoestrutura são praticamente inexistentes uma vez que é o vértice estratégico que avalia e coordena todo o centro operacional. Ao nível das escolas, poder-se-ão enquadrar algumas pequenas instituições de ensino particular nesta configuração.(Fig.7)

\subsection{Burocracia Mecanicista}

Esta configuração é caracterizada por uma grande dependência da estrutura hierárquica definida pelo organigrama, em que os fluxos são altamente regulados e a informação percorre a organização sempre de uma maneira formal, o que está associado a um processo pouco inovador. Os fluxos de autoridade partem do vértice numa direcção descendente e toda a comunicação dentro da estrutura efectua-se entre os elementos imediatamente acima ou abaixo na hierarquia definida. Este é um modelo que assenta numa estandardização dos processos de trabalhos e resultados (Mintzberg, 1995) em que todos os indivíduos têm as suas funções rigidamente definidas para a elaboração de um produto previamente concebido. (Fig.8)

Fig. 8

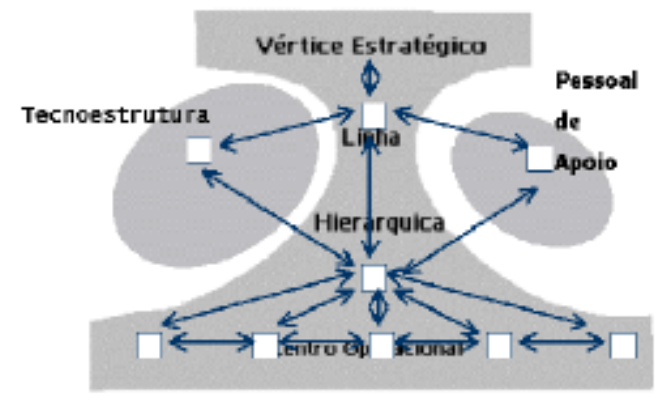

Fig. 9

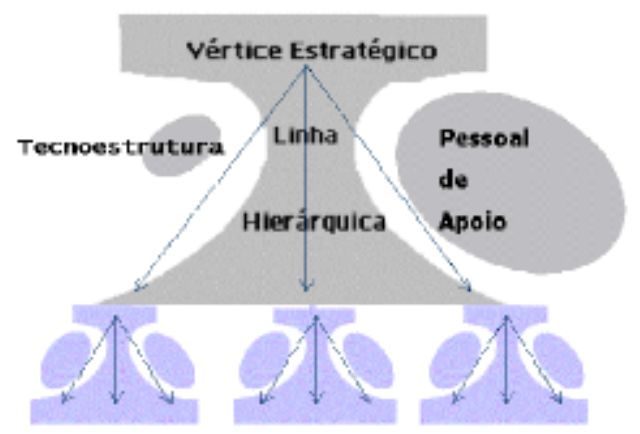




\subsection{Estrutura Divisionalisada}

Esta é uma configuração que não estando directamente associada ao funcionamento da escola, poderá aplicar-se à estrutura a nível macro do sistema de ensino. Pressupõe um vértice estratégico, que poderíamos considerar o Ministério da Educação que sendo o órgão de poder central, subdivide-se em diferentes departamentos, que poderíamos considerar as DRE's. A estrutura divisionalisada consiste na existência de diferentes departamentos que ao dispersarem as funções operacionais, minimizam a interdependência entre as divisões.(Mintzber,1995) (Fig.9).

\subsection{Burocracia Profissional}

Estando muito em voga nos tempos que correm, esta configuração é a que mais se enquadra no funcionamento da escola, em que o vértice estratégico tem, acima de tudo, uma função de coordenação do pessoal de apoio e gestão dos recursos financeiros e materiais, bem como o património da escola (Decreto-Lei 115-A/98), e é o centro operacional que se assume como componente-chave da organização. Os operacionais gozam de uma grande autonomia, graças à sua formação de base e como tal, há uma estandardização das qualificações. No caso dos professores, deixou de haver uma padronização do trabalho, que acarretava um elevadíssimo grau de exposição no que respeita à gestão escolar (Sergiovanni,2004) para passar a haver uma autonomia que permita aos professores adaptarem os currícula à realidade da sala de aula.

A inexistência de uma tecnoestrutura realça ainda mais as características da escola como uma burocracia profissional, sendo que o papel de analisar e avaliar o processo de produção (aprendizagens dos alunos), está entregue aos professores, dentro da sala de aula, ou em alguns casos ao corpo docente nas reuniões de conselho pedagógico.(Fig.10).

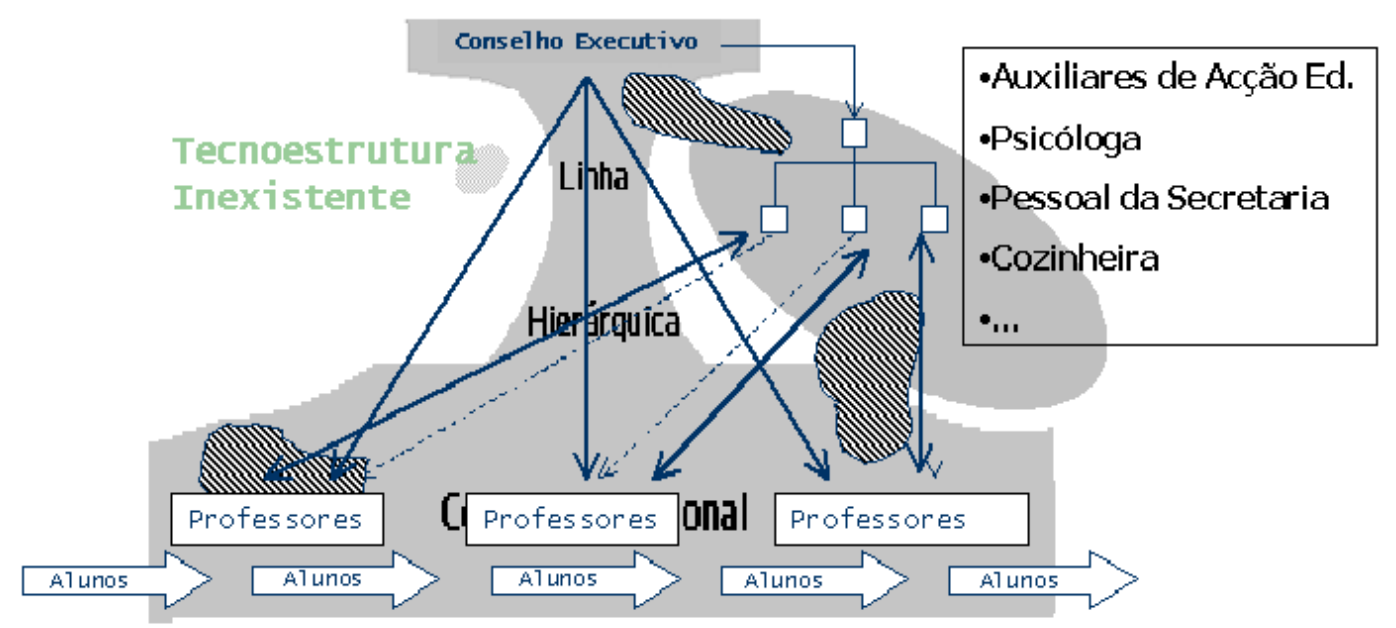

\subsection{Adhocracia}

Finalmente temos a Adhocracia que se assume claramente como a estrutura de amanhã e que para além das cinco partes da organização, contempla ainda o meio envolvente, atribuindo-lhe uma grande importância em todo o processo de produção. A Adhocracia pode ser caracterizada como uma configuração em que as diferentes partes da organizações se fundem numa estrutura amorfa e onde cada uma delas comunica directamente com as outras, mas também com o exterior. Esta é uma configuração que privilegia 
a inovação, pois a organização está constantemente a adaptar-se às necessidades e exigências, tanto externas como internas. Todos os fluxos de comunicação são de ordem informal e a coordenação é feita através de um ajustamento mútuo, o que beneficia a cooperação e o trabalho entre todos os elementos da organização em torno do projecto e missão a que ela se propõe. (Fig.11)

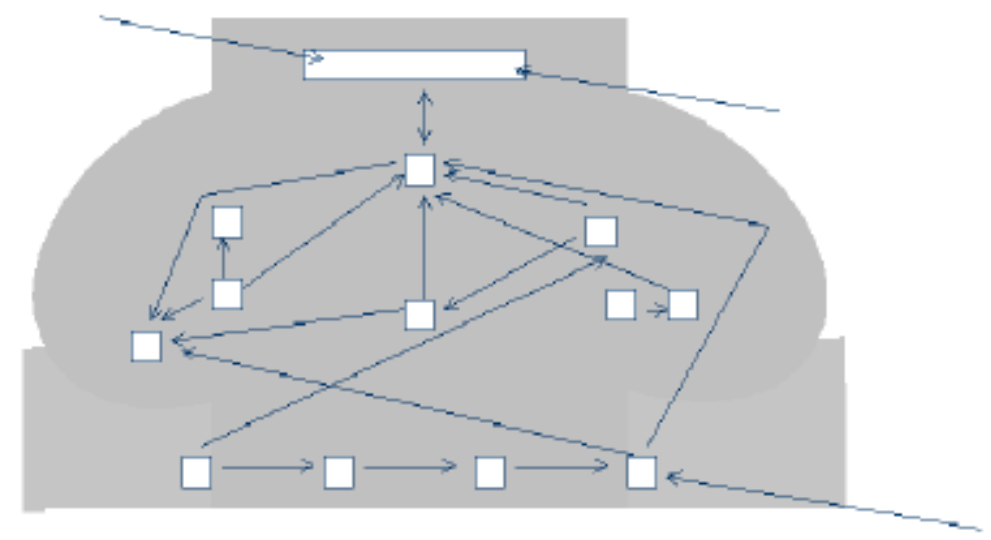

\section{ESCOLA BUROCRACIA VS. INOVAÇÃO}

Como se verificou anteriormente, a escola actual enquadra-se numa burocracia profissional. Porém, analisando documentos normativos, como o Decreto-Lei 115-A/98, Lei n.ำ4/99 ou até mesmo a Lei n.ำ 30/2002, que aprova o estatuto do aluno do ensino não superior, rapidamente nos apercebemos que pretende-se que a escola se articule com o meio envolvente e que o processo de aprendizagem contemple uma constante inovação e adaptação da organização escolar às necessidade individuais ou colectivas dos seus elementos ou comunidade que a rodeia.

No que respeita às relações interpessoais dentro das organizações escolares, a burocracia profissional é sem dúvida uma configuração que privilegia o individualismo, disfarçado sob o signo da autonomia, ou como afirma Hargreaves (1998), «Autonomia é a palavra delicada utilizada para mascarar a apreensão dos professores relativamente à sua avaliação e para a justificação à exclusão de observadores». A autonomia que é conferida aos profissionais não só serve como desculpa para os professores que resistem à mudança, como é por si só uma forma de evitar que os professores obtenham um feedback, por parte dos outros adultos de como está a decorrer todo o processo de ensino/aprendizagem (Hargreaves,1998). Sendo assim, permitirá a escola como burocracia profissional, cumprir o seu papel, num contexto de mudança e inovação decorrentes de um processo de adaptação a uma nova realidade social e cultural?

Analisando a última configuração de Mintzberg, a Adhocracia podemos encontrar algumas respostas às necessidade da escola actual, pois esta privilegia a inovação e a colaboração entre todos os indivíduos da organização em torno dos diferentes projectos existentes. Não querendo responder à questão de como deve a escola funcionar, se como burocracia profissional ou adhocracia, interessa reflectir sobre o que dela se deve esperar nos tempos que correm e sobretudo, qual o papel dos professores, como profissionais inseridos numa organização que deve garantir uma adaptação e inovação inerentes ao processo educativo. 


\section{CONCLUSÕES}

Numa concepção de escola moderna, adaptada à realidade do contexto em que cada instituição se insere e na qual há uma constante necessidade em se adaptar para melhor cumprir com as suas funções, poderemos pegar num termo apresentado por Argyris e Shön (1978) que é o de aprendizagem organizacional. Para estes autores, há aprendizagem organizacional quando a organização tenta corrigir os seus erros no confronto dos resultados esperados com a realidade. Sendo assim, a escola actualmente deve assumir uma estrutura que permita uma avaliação e posterior adaptação por forma a responder às exigências da sociedade moderna. Essa aprendizagem organizacional pode permitir uma mudança na forma dos professores e dos outros elementos da comunidade escolar agirem dentro da organização, mas depende ela também das atitudes dos diferentes intervenientes.

Neste contexto surge a cultura profissional da classe docente, que nos últimos anos tem sido objecto de estudo de muitos teóricos da educação, sendo cada vez mais consensual a ideia de que é necessária a criação de oportunidades para uma colegialidade reforçada capaz de gerar uma maior dependência entre professores e ao mesmo tempo, conduzir ao desenvolvimento das comunidades de ensino. (Sergiovanni, 2004). Contudo, os professores actualmente são pressionados a trabalhar em colaboração com os colegas(Little, 1990), o que como afirma Hargreaves (1998), levanta questões como os direitos do indivíduo e a protecção da individualidade face às pressões do grupo. Os professores que preferem planificar ou trabalhar grande parte do tempo sozinhos, correm o risco de ser ostracizados injustamente. Há ainda os casos em que os professores receiam o trabalho de equipa, pois preferem evitar o conflito uma vez que este é muitas vezes necessário para benefício da organização(Little, 1990) podendose mesmo dizer que os termos colaboração e consenso, geram inevitavelmente conflito (Achinstein, 2002). Desta forma, Little afirma também que entre os professores deve haver formas de colegialidade que denomina de "fortes" e que são caracterizadas por quatro tipos de interacções: contar histórias e procurar ideias; ajuda e apoio; partilha de materiais e experiências e finalmente o que gera o termo colaboração, o trabalho de grupo. No fundo e pegando em algumas ideias de Jurgen Habermas é necessária uma interacção comunicativa, em que os professores busquem conjuntamente coordenar e justificar acções pedagógicas, a partir da troca de conhecimentos e enfoques, inerentes a cada disciplina, partilhando e planeando experiências integradas(Gonçalves, 1999)

Voltamos atrás, à definição de organização dada por Morgan (1996) a escola deve funcionar como um sistema vivo que existe num ambiente mais amplo do qual depende em termos de satisfação das suas várias necessidades e os seus profissionais devem funcionar como os órgãos que, em conjunto, trabalham para que a organização cumpra com os seus objectivos.

Em suma, uma organização que educa deve assentar nos seguintes pilares: a racionalidade, como a disposição lógica dos elementos da organização; a flexibilidade, como a capacidade de adaptar-se às necessidades; a permeabilidade ou abertura em relação ao espaço exterior e a colegialidade para fazer frente ao individualismo, criado pela fragmentação de espaços, horários e mecanismos de colaboração.(Santos, 1995 in Gairin, 2000)

Temos portanto de considerar que as organizações educativas são por excelência, sistemas de aprendizagem organizacional, se atendermos à qualificação e autonomia dos seus profissionais, à sua ligação permanente ao conhecimento, à centralidade das relações interpessoais e intergrupais nos seus 
processos de trabalho e às finalidades educativas e sociais que estão na base da sua legitimação pela sociedade (Santiago, 2000)

\section{BIBLIOGRAFIA}

ACHInsteIn, Betty, (2002), Conflict Amid Community: The micropolitics of teacher collaboration, Columbia: Teachers College Records, Volume 104, 3, 421-455

ARGYRIS \& SHÖN, (1978), Organizational learning: a theory of action perspective. Em Alarcão, Isabel, Escola Reflexiva e Supervisão, Porto: Porto Editora

Chanlat, Jean François, (1993), O indivíduo nas organizações. Em Pereira, Luiz Alberto (2003), Poder e clima organizacional: um estudo de caso em uma empresa petroquímica, Tese de Mestrado Inédita, Salvador: Universidade Federal da Bahia

DeCRETo-Lel 115-A/98 de 4 de Maio (Regime Jurídico de Autonomia e Gestão)

ETZıONI, Amitai, (1984), Organizações Modernas. Em Costa, Jorge Adelino, 1996, Imagens Organizacionais da Escola, Porto: Edições Asa

Gonçalves, Maria Salin (1999), Teoria da ação comunicativa de Habermas: Possibilidades de uma ação educativa de cunho interdisciplinar na escola, Educação \& Sociedade, 66, 125-140

HaRgReAVes, Andy (1998), Os professores em tempos de mudança, Lisboa: Macraw Hill de Portugal

(Trabalho original em inglês publicado em 1994)

LEI n.ำ24/99 de 22 de Abril (Alteração ao Decreto-Lei 115-A/98)

LEI n.. 30/2002 de 20 de Dezembro (Estatuto do Aluno de ensino não superior)

LEI n.․ 46/86 de 14 de Outubro (Lei de Bases do Sistema Educativo)

LITTLE, Judith Warren (1990), The Persistence of Privacy: Autonomy and Initiative in Teachers' Professional Relations, Teachers College Record, Volume 91, 4, 509-536

LOUREIRO, Carlos, (2001), A docência como profissão, Porto: Edições Asa

MintZBerg, Henry, (1995), Estrutura e Dinâmica das Organizações, Lisboa: Publicações Dom Quixote . (Trabalho original em inglês publicado em 1979).

MoRGAN, G., (1996), Imagens da Organização, São Paulo: Atlas

SANTIAGO, Rui (2000), A escola também é um sistema de aprendizagem organizacional. Em Alarcão, Isabel, Escola Reflexiva e Supervisão, Porto: Porto Editora

SANTOS, (1995), Organizaciones que Educan. Em Gairín, Joaquín, (2000), Cambio de cultura y organizaciones que aprenden apresentada no III Congreso internacional sobre dirección de centros educativos: liderazgo y organizaciones que aprenden, Universidad de Deusto, Bilbao

SergiovanNI, Thomas, (2004), O mundo da liderança, Porto: Edições Asa. (Trabalho original em inglês publicado em 2000) 


\title{
Contactar
}

Revista lberoamericana de Educación

\author{
Principal OEI
}

